\title{
Determinants of Perinatal Mortality in Public Hospitals of lluu Abbaa Boor Oromia Region, South West Ethiopia, 2019: Unmatched Case- Control Study
}

\section{Abdi Geda \\ Shuayib Shemsu \\ Rukiya Debalke}

Public Health Department, College of Health Science, Mettu University, Mettu, Oromia Region, Ethiopia
Correspondence: Abdi Geda Public Health Department, College of Health Science, Mettu University, PO Box: 318, Mettu, Oromia Region, Ethiopia Email abdi.geda@meu.edu.et
Background: Globally, about 2.5 million children die in the first month after birth; this amounts to 7000 neonatal deaths every day. Almost half of neonatal deaths occur on the first postnatal day, and the vast majority of the rest occurs within the first postnatal week. In Ethiopia, efforts to reduce perinatal mortality did not meet the United Nations Millennium Development Goal (MDG) in 2020.

Objective: To identify determinants of perinatal death in public hospitals of Iluu Abbaa Boor Zone, Oromia regional state, Southwest Ethiopia, 2019.

Methods: An institution-based, case-control study was employed from March 1 to April 30, 2019 in Iluu Abbaa Boor Zone governmental hospitals. A total of 90 cases were taken consecutively. Four controls were assigned for each case. Maternal and neonatal data were collected by interview using a semi-structured questionnaire and hospital record review.

Results: The likelihood of perinatal mortality was 2.8 times greater for those whose mothers did not have regular ANC follow-up (AOR 2.8; 95\% CI [1.4-4.8]). The odds of perinatal mortality were 2.8 times higher among newborns of mothers with less than two years birth interval (AOR 2.8; 95\% CI [1.8-12.4]). The odds of perinatal mortality were 14.3 times higher among preterm deliveries compared to newborns with term deliveries (AOR 14.3; 95\% CI [4.7-37.7])

Conclusion: In a medical resource-limited region of Ethiopia, not having ANC follow-up, short birth interval, preterm and postterm births, maternal hemoglobin level, use of partograph, were independent determinants of perinatal mortality. Targeting education and medical resources in these areas for women in the reproductive age group could influence regional perinatal mortality.

Keywords: perinatal death, determinants, Ilu Ababor, Ethiopia

\section{Background}

Globally, about 2.5 million children die in the first month after birth; this amounts to 7000 neonatal deaths every day. Almost half of neonatal deaths occur on the first postnatal day, and the vast majority of the rest occur within the first postnatal week. ${ }^{1,3}$ Among the Sustainable Development Goal regions, sub-Saharan Africa had the highest neonatal mortality rate in 2017 with 27 deaths per 1000 live births, followed by Southern Asia, Oceania, Latin America and the Caribbean with 26, 21, and 10 deaths per live birth respectively. ${ }^{7-12}$ A child born in sub-Saharan Africa or 
in Southern Asia is nine times more likely to die in the first month than a child born in high-income countries. ${ }^{2,13}$

The 2016 Ethiopian Demographic and Health Survey (EDHS) results showed a perinatal death rate of 33 per 1000 live births. This means in Ethiopia, 1 in every 30 children die within the first week after being born. The perinatal death rate outpaces under five mortality. More than $43 \%$ of infants die in the first month while the remaining (57\%) die during the following 59 months. ${ }^{4-6}$ Further, in Ethiopia, efforts to reduce perinatal mortality did not meet the United Nations Millennium Development Goal (MDG) in 2020. ${ }^{5}$

Our review of the literature indicates that there are important gaps in understanding the determinants of perinatal health and mortality in medical resource-limited regions. We investigated perinatal health status in the Iluu Abbaa Boor Zone, Oromia Region, of Southwest Ethiopia, using a different approach and study design from previous work. Previous studies analyzed cross-sectional data collected from mother/care taker or from maternal records only. In this study we reviewed and analyzed data from a structured care taker interview as well as neonatal hospital records. ${ }^{14-18}$

We embarked on this study to identify maternal and newborn determinants of perinatal mortality to inform health care providers and motivate policy makers to take action to reduce preventable causes of death and improve perinatal survival.

\section{Methods and Materials}

Unmatched case-control study was conducted in Iluu Abbaa Boor Zone of Oromia Region, Southwest Ethiopia. The capital of the zone, Mettu town, is located $600 \mathrm{~km}$ southwest of the capital Finfinnee/Addis Ababa. Iluu Abbaa Boor Zone is one of the well-known coffee producing areas in the western part of the region and lies between $34^{\circ} 52^{\prime} 12^{\prime \prime}$ E to $41^{\circ} 34^{\prime} 55^{\prime \prime} \mathrm{E}$ longitude and $7^{\circ} 27^{\prime} 40^{\prime \prime} \mathrm{N}$ to $9^{\circ} 02^{\prime}$ $10^{\prime \prime} \mathrm{N}$ latitude. The zone is bordered by Gambella Region in the West, Bunno Bedele Zone in the Southeast, West Wollega in the North, East Wollega in the Northeast and Southern Nations Nationalities and Peoples' Region in the South. The estimated area of Ilu Ababor Zone based on the current border delimitation is $16,884.4 \mathrm{~km}^{2}$.

There are 2 government hospitals in the Zone. These hospitals are; Metu Karl Referral Hospital and Darimu Hospital. The NICUs of both hospitals receive high risk babies delivered within the institution, referrals from other health facilities, and referrals from home deliveries.
All deliveries conducted in the study hospital during the study period were considered as a population from which study subjects were drawn. Cases were perinatal deaths, whereas controls were live births who survived until 7 days of age, while randomly selected Cases were both still-births and early newborn deaths and Controls were considered those live births cleared/ discharged from the hospital who survived until 7 days of age, were considered as populations of interest. The inclusion criteria defined for the cases and controls were single pregnancies, and babies weighing over $500 \mathrm{~g}$ and/or of gestational age $\geq 28$ weeks.

\section{Sample Size and Sampling Procedure}

The minimum required sample size for this study was determined by using Epi-Info V.7 by considering two sample comparisons of double population proportions based on the following assumptions, the ratio of cases to control was 1:4, 95\% confidence interval, $80 \%$ power level, $10 \%$ non-response rate and considering different explanatory variables from previously published research in Addis Ababa like partograph use and ANC follow-up; four hundred and eighty five, out of which 97 were cases and were 388 controls, was determined as final sample size for the this study. Samples were allocated proportional to the two hospitals (Darimu and Karl Hospitals) considering flow of patients (proportion of patients that visit these hospitals). From a total of 388 controls, 242 were allocated to Matu Karl Hospital and 126 were allocated to Darimu Hospital. Out of the 97 calculated sample size for cases, 64 were allocated to Karl hospital and 33 cases were allocated to Darimu Hospital. Cases were selected consecutively until the desired sample size was acquired, while systematic random sampling method was applied to select the controls. Every fourth mother was interviewed and record reviewed at Karl hospital while every second mother was interviewed and record reviewed at Darimu Hospital using well-structured questionnaire and checklist.

Kebeles Health extension worker verified that infants discharged from hospital survived up to 7 days. Cases were mothers who experienced stillbirth or early neonatal death either at home or in hospital (death within 7 days after birth) while Controls were mothers with neonates who survived beyond seven days after birth.

NB: regarding early neonatal death, those neonates who were discharged from hospital before seven days were followed-up by telephone call to check whether or not they survived beyond 7 days after discharge. Non- 
respondent mothers were those who did not respond to telephone calls or if they were not present during home visit by the health extension worker.

\section{Data Collection Procedure}

A well-structured tool was adapted and pretested on ten percent of the sample size outside of the study area. Then it was administered by an interviewer to collect data from mothers/care givers. Medical records of mothers and neonates were reviewed by trained neonatal nurses and midwives. The questionnaire contained socio demographic information which includes age, sex, marital status, level of education, family size, and residence. History of treatment such as inpatient care, a graphical record of labor, summary report of delivery and notes regarding antenatal care (ANC) follow-up were recorded.

\section{Data Analysis Procedure}

Data were cleaned, edited, coded, and entered into Epi data version 3.1 and exported to SPSS for windows version 20 for analysis. Exploratory data analysis was carried out to check the levels of missing values, presence of influential outliers. Multicollinearity was checked using scatter plot and correlation matrix of the factors. Descriptive statistics were done using frequency with percentage and standard deviation.

Cross-tabulation and bivariate logistic regression analysis were done to see the association between individual explanatory and outcome variables, variables with P-value $<0.25$ were candidates for multivariable logistic regression. Odds ratio with $95 \%$ C.I was used to measure the strength of association between dependent and independent variables. Hosmer and Lemeshow test was used to see model fitness. $\mathrm{P}$ value $<0.05$ was used to declare level of statistical significance.

\section{Ethical Consideration}

This study was conducted as per the Helsinki Declaration. The proper ethical support was realized from the Research Ethical Committee of Mettu University. Permission letter was written to both Mettu Karl Referral and Darimu Hospital from The Iluu Abbaa Boor Zonal Health Office. Then written informed consent was obtained from the participants who were interviewed face to face and oral informed consent was obtained for those who were interviewed by telephone call after the necessary explanation about the purpose and benefits of the study and their right on decision to participate in the study. All the interviews with respondents were done under strict privacy.

\section{Result}

\section{Socio Demographic Characteristics}

A total of 450 (90 cases and 360 control) mothers were interviewed from 485 , a response rate of $92.5 \%$. The mean age of the mothers for cases and controls was $25.2+4.5$ and $26.2+4.8$ respectively. From the total mothers, $30 \%$ of cases and $31.4 \%$ of controls were between the age group of 20-24 years followed by $35-39$ years $(21.1 \%$ in control and $26.7 \%$ in cases). Three hundred and thirty-three (92.5\%) controls and $83(92.3 \%)$ cases were married. Seventy-eight $(87.6 \%)$ cases and two hundred and fortyfour $(67.8 \%)$ controls were house wives whereas government employees accounted for $3.3 \%$ of cases and $15.4 \%$ of controls respectively. Mothers who completed college education and higher made up $18.8 \%$ of cases and $110.7 \%$ of controls (Table 1).

\section{Obstetrics Characteristics}

Among the total respondents, 288 mothers had past delivery history: 121 controls and 39 cases gave birth less than 2 years after their previous delivery. Mothers who had regular antenatal care schedule (four ANC visits for pregnant women's with no complications) and took TT vaccination for the recent delivery made up $82.9 \%$.

Of the mothers, three hundred and seventy four $(83.1 \%)$ delivered at term. Considering preterm delivery, $64.4 \%$ was observed in cases and about $1.7 \%$ in controls. Three hundred and ninety-nine $(88.7 \%)$ mothers delivered normally by spontaneous vaginal delivery, $6.7 \%$ by cesarean section, and $3.6 \%$ were instrumental deliveries (forceps or vacuum), while assisted breech delivery accounted for $1.1 \%$. One hundred and twenty (26.6\%) mothers had previous history of abortion. From the total respondents, $12.2 \%$ of the cases had history of stillbirth and $7.8 \%$ experienced an early neonatal death. Likewise from the total respondents, $4.1 \%$ of controls had history of stillbirth and early neonatal death (Table 2).

\section{Coexisting Medical and Obstetric Conditions}

A total of four hundred and eleven mothers were screened for HIV, VDRL, and Hepatitis B Virus. Out of this, $4(4.5 \%)$ cases and $21(5.8 \%)$ controls were 
Table I Sociodemographic Characteristics of Mothers who Experienced Perinatal Deaths (Cases), and Controls Among Deliveries in Public Hospitals in Iluu Abbaa Boor Zone, Oromia, South West Ethiopia, 2019

\begin{tabular}{|c|c|c|c|c|}
\hline \multirow[t]{2}{*}{ Variables } & \multirow[t]{2}{*}{ Category } & \multicolumn{3}{|c|}{ Perinatal Outcome } \\
\hline & & Control & Case & Total \\
\hline \multirow[t]{6}{*}{ Maternal age } & $<19$ & $20(5.5 \%)$ & $13(14.4)$ & $33(7.4 \%)$ \\
\hline & $20-24$ & $113(31.4 \%)$ & $27(30 \%)$ & $140(31.1 \%)$ \\
\hline & $25-29$ & $61(16.9 \%)$ & $6(6.7 \%)$ & $67(14.9 \%)$ \\
\hline & $30-34$ & $82(22.8 \%)$ & $6(6.7 \%)$ & $88(19.6 \%)$ \\
\hline & $35-39$ & $76(21.1 \%)$ & $24(26.7 \%)$ & $100(22.2 \%)$ \\
\hline & $<40$ & $8(2.2 \%)$ & I4(I5.5\%) & $22(4.8 \%)$ \\
\hline \multirow[t]{4}{*}{ Marital status } & Married & $333(92.5 \%)$ & $83(92.3 \%)$ & $416(92.4 \%)$ \\
\hline & Single & $5(1.4 \%)$ & $3(3.3 \%)$ & $8(1.8 \%)$ \\
\hline & Widowed & $13(3.6 \%)$ & $3(3.3 \%)$ & $16(3.5 \%)$ \\
\hline & Divorced & $9(2.5 \%)$ & $\mathrm{I}(\mathrm{I} . \mathrm{I} \%)$ & $10(2.2 \%)$ \\
\hline \multirow[t]{6}{*}{ Occupational status } & House wife & $244(67.8 \%)$ & $78(86.7 \%)$ & $322(71.5 \%)$ \\
\hline & Private employee & $8(2.3 \%)$ & & $8(1.8 \%)$ \\
\hline & Government employee & $55(15.24 \%)$ & $3(3.3 \%)$ & $58(12.9 \%)$ \\
\hline & Daily laborer & $22(6.1 \%)$ & $8(8.8 \%)$ & $30(6.6 \%)$ \\
\hline & Merchant & $7(1.9 \%)$ & 0 & $7(1.5 \%)$ \\
\hline & Student & $24(6.6 \%)$ & $\mathrm{I}(\mathrm{I} . \mathrm{I} \%)$ & $25(5.5 \%)$ \\
\hline \multirow[t]{5}{*}{ Educational status } & Cannot read and write & $25(6.9 \%)$ & $23(25.5 \%)$ & $48(10.7 \%)$ \\
\hline & Read and write & $123(34.2 \%)$ & $31(34.4 \%)$ & I54(34.2\%) \\
\hline & Primary & $83(23 \%)$ & $6(6.6 \%)$ & $89(19.7 \%)$ \\
\hline & Secondary & $87(24.2 \%)$ & $13(14.4 \%)$ & $100(22.2 \%)$ \\
\hline & Collage and above & $42(11.7 \%)$ & $17(18.8 \%)$ & $59(13.1 \%)$ \\
\hline
\end{tabular}

reactive for $\mathrm{HIV}$, making the total number of $\mathrm{HIV}$ reactive mothers $25 \quad(5.5 \%)$, while $39 \quad(8.7 \%)$ participants were "unknown" and the rest were nonreactive.

Four $(4.5 \%)$ cases and $5(1.4 \%)$ controls were reactive for venereal disease research laboratory (VDRL) test, 76 (16.9\%) participants were "unknown" while the remaining were negative. Three $(3.4 \%)$ cases and five $(3.8 \%)$ controls were positive for hepatitis B surface antigen testing, $87(19.4 \%)$ were "unknown" and the rest were negative (Table 3).

Hemoglobin levels were determined for $63.4 \%$ of the cases and for $85.8 \%$ of the controls during ANC followup or before delivery. The minimum level of hemoglobin was $4 \mathrm{gm} / \mathrm{dl}$ and maximum $17 \mathrm{gm} / \mathrm{dl}$. Proportion of anemia was $36.5 \%$ of cases and $14 \%$ of controls (Figure 1).

From the 90 cases and 360 controls, 78 (86.6\%) and $115(32 \%)$ had different types of obstetric complications respectively. Out of obstetric complications, preterm labor was more common among cases $(38(48.8 \%))$ versus $(6(5.2 \%))$ controls. On the other hand, preeclampsia and eclampsia were common among controls with $43(37.4 \%)$ and $22(19.2 \%)$ respectively. While the rest of the obstetric complication variables were almost similarly distributed among the cases and controls (Table 4).

\section{Newborn Factors}

Among the total 90 cases, $56 \quad(62.2 \%)$ were stillbirths while the rest, 34 (37.8\%), were neonatal deaths. Cephalic presentation accounted for $94.1 \%$ among controls and $86.7 \%$ among cases. Sixty (66.6\%) cases and $202(56.1 \%)$ controls were female. Very low birth weight and low birth weight newborns were more common in cases and accounted for $2.2 \%$ and $77.8 \%$ respectively. Congenital anomalies were recorded in $17.8 \%$ of the cases (Table 5).

\section{Health Care Related Factors}

Partograph was used in 318 (70.7\%) of the total study subjects. The proportion of mothers who delivered without partograph follow-up was $35(38.9 \%)$ in cases and 76 $(21.1 \%)$ in control groups. For $4.7 \%$ of mothers 
Table 2 Obstetric Characteristics of Mothers with Perinatal Deaths (Cases) and Controls Among Public Hospital Deliveries in Iluu Abbaa Boor Zone, South West Ethiopia, 2019

\begin{tabular}{|c|c|c|c|c|}
\hline \multirow[t]{2}{*}{ Variables } & \multirow[t]{2}{*}{ Category } & \multicolumn{2}{|c|}{ Perinatal Outcome } & \multirow[t]{2}{*}{ Total } \\
\hline & & Control & Case & \\
\hline \multirow[t]{3}{*}{ Parity } & I & $128(35.6 \%)$ & $34(37.8 \%)$ & $162(36 \%)$ \\
\hline & $2-4$ & $204(56.6 \%)$ & $45(50 \%)$ & $249(55.3 \%)$ \\
\hline & $>5$ & $28(7.8 \%)$ & $\mathrm{II}(\mathrm{I} 2.2 \%)$ & $39(8.7 \%)$ \\
\hline \multirow[t]{2}{*}{ Birth interval } & $<2$ years & $121(33.6 \%)$ & 39 (43.3\%) & $160(35.5 \%)$ \\
\hline & $>2$ years & III (30.8\%) & 17 (I8.8\%) & $128(28.4 \%)$ \\
\hline \multirow[t]{2}{*}{ ANC follow-up } & Yes & $312(86.7 \%)$ & $61(67.8 \%)$ & $373(82.9 \%)$ \\
\hline & No & $48(13.3 \%)$ & $29(32.2 \%)$ & $77(17.1 \%)$ \\
\hline \multirow[t]{2}{*}{ TT vaccination } & Yes & $312(86.7 \%)$ & $61(67.8 \%)$ & $373(82.9 \%)$ \\
\hline & No & $48(13.3 \%)$ & $29(32.2 \%)$ & $77(17.1 \%)$ \\
\hline \multirow[t]{3}{*}{ Gestational age } & $28-36$ & $6(1.7 \%)$ & $58(64.4 \%)$ & $64(14.2 \%)$ \\
\hline & $37-41$ & $348(96.6 \%)$ & $26(28.9 \%)$ & $374(83.1 \%)$ \\
\hline & $>42$ & $6(1.7 \%)$ & $6(6.7 \%)$ & $12(2.7 \%)$ \\
\hline \multirow[t]{5}{*}{ Mode of delivery } & Spontaneous Vaginal Delivery & $333(92.5 \%)$ & $66(73.3 \%)$ & $399(88.7 \%)$ \\
\hline & Forceps delivery & $3(0.86 \%)$ & 0 & $3(0.7 \%)$ \\
\hline & Vacuum delivery & $5(1.5 \%)$ & $8(8.8 \%)$ & $13(2.9 \%)$ \\
\hline & Cesarean section & $16(4.4 \%)$ & $14(\mid 5.6 \%)$ & $30(6.7 \%)$ \\
\hline & Assisted breech delivery & $3(0.84 \%)$ & $2(2.3 \%)$ & $5(1.1 \%)$ \\
\hline \multirow[t]{2}{*}{ History of abortion } & Yes & $88(24.4 \%)$ & $32(35.5 \%)$ & $120(26.6 \%)$ \\
\hline & No & $272(75.6 \%)$ & $58(64.5 \%)$ & $330(73.4 \%)$ \\
\hline \multirow[t]{2}{*}{ Previous history of stillbirth } & Yes & $15(4.1 \%)$ & $\mathrm{II}(\mathrm{I} 2.2 \%)$ & $26(5.8 \%)$ \\
\hline & No & $345(95.9 \%)$ & $79(87.8 \%)$ & $424(94.2 \%)$ \\
\hline \multirow[t]{2}{*}{ Previous History of ENND } & Yes & $15(4.1 \%)$ & $7(7.8 \%)$ & $22(4.9 \%)$ \\
\hline & No & $345(95.9 \%)$ & $83(92.2 \%)$ & $428(95.1 \%)$ \\
\hline
\end{tabular}

Table 3 HIV, VDRL, and Hepatitis B Status of Mothers with Perinatal Deaths (Cases) and Controls Among Public Hospital Deliveries in Iluu Abbaa Boor Zone, South West Ethiopia, 2019

\begin{tabular}{|c|c|c|c|c|}
\hline \multirow[t]{2}{*}{ Variables } & \multirow[t]{2}{*}{ Category } & \multicolumn{2}{|c|}{ Perinatal Outcome } & \multirow[t]{2}{*}{ Total } \\
\hline & & Control & Case & \\
\hline \multirow[t]{3}{*}{ HIV } & Reactive & $2 \mathrm{I}(5.8 \%)$ & $4(4.5 \%)$ & $25(5.5 \%)$ \\
\hline & Non-reactive & $318(88.4 \%)$ & $68(75.5 \%)$ & $386(85.8 \%)$ \\
\hline & Unknown & $2 \mathrm{I}(5.8 \%)$ & $18(20 \%)$ & $39(8.7 \%)$ \\
\hline \multirow[t]{3}{*}{ VDRL } & Reactive & $5(1.4 \%)$ & $4(4.4 \%)$ & $9(2 \%)$ \\
\hline & Non-reactive & $307(85.3 \%)$ & $58(64.5 \%)$ & $365(81.1 \%)$ \\
\hline & Unknown & $48(13.3 \%)$ & $28(31.1 \%)$ & $76(16.9 \%)$ \\
\hline \multirow[t]{3}{*}{ Hepatitis B } & Positive & |4(3.8\%) & $3(3.4 \%)$ & $17(3.7 \%)$ \\
\hline & Negative & $287(79.8 \%)$ & $59(65.5 \%)$ & $346(76.9 \%)$ \\
\hline & Unknown & $59(16.4 \%)$ & $28(31.1 \%)$ & $87(19.4 \%)$ \\
\hline
\end{tabular}

partograph was not indicated because of different obstetric factors that did not allow the mother to go into labor (Table 6).
From fifty-six stillbirths, $22(39.3 \%)$ of them were admitted to the hospital with positive fetal heart beat and later reported as stillbirth during the course of labor and 




Figure I Hemoglobin level of cases and controls in Hospital deliveries at lluu Abbaa Boor Zone, South West Ethiopia, 2019.

delivery and the rest $34(60.7 \%)$ were admitted with intra uterine fetal death.

\section{Factors Associated with Perinatal Mortality}

Binary logistic regression was done to see the association of perinatal mortality with different factors. Accordingly, maternal age, educational status, birth interval, ANC follow-up, TT vaccination, gestational age, history of

Table 4 Types of Obstetric Complications of Mothers with Perinatal Deaths (Cases) and Controls Among Public Hospital Deliveries in Iluu Abbaa Boor Zone, South West Ethiopia, 2019

\begin{tabular}{|l|l|l|}
\hline Obstetric Complications & $\begin{array}{l}\text { Perinatal } \\
\text { Outcome }\end{array}$ & \\
\cline { 2 - 3 } & $\begin{array}{l}\text { Among } \\
\text { Controls }\end{array}$ & $\begin{array}{l}\text { Among } \\
\text { Cases }\end{array}$ \\
\hline Preeclampsia & $43(37.4 \%)$ & $10(12.9 \%)$ \\
Eclampsia & $22(19.1 \%)$ & $6(7.7 \%)$ \\
Ante-partum hemorrhage & $11(9.6 \%)$ & $7(9 \%)$ \\
Post-partum hemorrhage & $12(10.4 \%)$ & $6(7.7 \%)$ \\
Obstructed labor & $3(2.6 \%)$ & $2(2.6 \%)$ \\
Uterine rupture & $2(1.8 \%)$ & $1(1.3 \%)$ \\
Gestational diabetes mellitus & $5(4.4 \%)$ & 0 \\
Polyhydraminos & 0 & $2(2.6 \%)$ \\
Oligohydraminos & $2(1.8 \%)$ & 0 \\
Post-term & $3(2.6 \%)$ & $3(3.8 \%)$ \\
PROM & $6(5.2 \%)$ & $3(3.8 \%)$ \\
Preterm labor & $6(5.2 \%)$ & $38(48.8 \%)$ \\
Total number of mothers with & $115(32 \%)$ & $78(86.6 \%)$ \\
obstetric complications & & \\
\hline
\end{tabular}

stillbirth, level of hemoglobin, history of obstetric complications, sex and weight of newborns, newborns delivered with congenital anomaly, and use of partograph showed significant association.

Variables with p-value less than 0.25 on bivariate analysis were entered into multivariable analysis. Among these variables; birth interval, regular ANC follow-up, obstetric complication, gestational age, anemia, and use of partograph were the independent predictors of perinatal mortality.

The odds of perinatal mortality were 2.8 times higher among newborns of mothers with less than two years birth interval compared to those whose previous birth interval was more than or equal to two years (AOR 2.8; 95\% CI $(1.8-12.4))$.

The odds of perinatal mortality were 2.8 times higher among newborns whose mothers did not have regular ANC follow-up compared to those whose mothers had regular ANC follow-up (AOR 2.8; 95\% CI (1.4-4.8)).

The odds of perinatal mortality were 14.3 times higher among preterm deliveries compared to newborns with term deliveries (AOR 14.3; 95\% CI (4.7-37.7)). The odds of perinatal mortality were 2.5 higher among newborns whose mothers had obstetric complication compared to newborns whose mothers had no obstetric complication (AOR 2.5; 95\% CI (1.9-22.7)). Newborns born to anemic mothers were about 3 times more likely to die compared to newborns born to mothers who did not have anemia (AOR 2.8; 95\% CI (1.4-5.71)).

The odds of perinatal mortality were two times higher among newborns whose mothers' labor was not followed 
Table 5 Newborn Characteristics of Perinatal Deaths (Cases) and Controls Among Public Hospital Deliveries in lluu Abbaa Boor Zone, South West Ethiopia, 2019

\begin{tabular}{|c|c|c|c|c|}
\hline \multirow[t]{2}{*}{ Variables } & \multirow[t]{2}{*}{ Category } & \multicolumn{2}{|c|}{ Perinatal Outcome } & \multirow[t]{2}{*}{ Total } \\
\hline & & Control & Case & \\
\hline Fetal Presentation & $\begin{array}{l}\text { Cephalic } \\
\text { Breech } \\
\text { Transverse }\end{array}$ & $\begin{array}{l}339(94.1 \%) \\
17(4.8 \%) \\
4(1.1 \%)\end{array}$ & $\begin{array}{l}78(86.7 \%) \\
\mathrm{II}(\mathrm{I} 2.2 \%) \\
\mathrm{I}(\mathrm{I} .3 \%)\end{array}$ & $\begin{array}{l}417(92.7 \%) \\
28(6.2 \%) \\
5(1.1 \%)\end{array}$ \\
\hline Sex & $\begin{array}{l}\text { Male } \\
\text { Female }\end{array}$ & $\begin{array}{l}158(43.9 \%) \\
202(56.1 \%)\end{array}$ & $\begin{array}{l}60(66.6 \%) \\
30(33.3 \%)\end{array}$ & $\begin{array}{l}218(48.4 \%) \\
232(51.6 \%)\end{array}$ \\
\hline Weight & $\begin{array}{l}\text { Very low BW (1000-1499gm) } \\
\text { Low BW (1500-2499gm) } \\
\text { Normal BW (2500-3999gm) } \\
\text { Macrosomic (>4000gm) }\end{array}$ & $\begin{array}{l}0 \\
25(7 \%) \\
332(92.2 \%) \\
3\end{array}$ & $\begin{array}{l}2(2.2 \%) \\
70(77.8 \%) \\
18(20 \%) \\
0\end{array}$ & $\begin{array}{l}2 \\
95(21.1 \%) \\
350(77.8 \%) \\
3\end{array}$ \\
\hline Congenital anomaly & $\begin{array}{l}\text { Yes } \\
\text { No }\end{array}$ & $\begin{array}{l}4(1.1 \%) \\
356(98.9 \%)\end{array}$ & $\begin{array}{l}16(17.8 \%) \\
74(82.2 \%)\end{array}$ & $\begin{array}{l}20(4.5 \%) \\
430(95.5 \%)\end{array}$ \\
\hline
\end{tabular}

Abbreviation: BW, birth weight.

Table 6 Use of Partograph for Mothers who Experienced Perinatal Deaths (Cases) and Controls Among Public Hospital Deliveries in Iluu Abbaa Boor Zone, South West Ethiopia, 2019

\begin{tabular}{|l|l|l|l|l|}
\hline \multirow{2}{*}{ Variables } & \multirow{2}{*}{ Category } & \multicolumn{2}{|l|}{ Perinatal Outcome } & \multirow{2}{*}{ Total } \\
\cline { 3 - 4 } & & Control & Case & \\
\hline Use of & Yes & $272(75.6 \%)$ & $46(51.1 \%)$ & $318(70.7 \%)$ \\
partograph & No & $76(21.1 \%)$ & $35(38.9 \%)$ & $111(24.6 \%)$ \\
& Not & $12(3.3 \%)$ & $9(10 \%)$ & $21(4.7 \%)$ \\
& indicated & & & \\
\hline
\end{tabular}

using partograph than newborns whose mothers' labor was followed by partograph (AOR 2.0; 95\% CI (1.274-15.4)) (Table 7).

\section{Discussion}

This study was conducted in a medical resource-limited region in Ethiopia, we found perinatal mortality was 2.8 times higher among newborns with a maternal birth interval of less than 2 years when compared to a birth interval greater than or equal to two years (AOR 2.8; $95 \% \mathrm{CI}$ (1.84-12.44)). This finding is consistent with case-control studies done Addis Ababa, Northwest Ethiopia, and metaanalysis done in sub-Saharan Africa, but different from another study done in Ethiopia utilizing EDHS data. The possible explanation for this difference could be due to difference in study design. ${ }^{17,18}$

ANC follow-up benefits both the mother and the baby; it assists in screening, diagnosing and managing or controlling the risk factors that might adversely affect the pregnant woman and/or the pregnancy outcome. The present study also identified regular ANC follow-up as independent predicting factor, accordingly perinatal mortality was 2.8 times higher among mothers who did not have regular ANC follow-up (AOR 2.84; 95\% CI (1.44-4.83)). This finding is consistent with studies done in southwest Ethiopia and Zimbabwe. The possible explanation for this is that ANC follow-up allows for earlier detection and management of pregnancy complications that could affect birth outcomes. ${ }^{18,20}$

Premature birth is a known determinant for perinatal death even in facilities with advanced neonatal care capabilities. In rural areas where advanced neonatal care is not available, prematurity is an even greater contributor to neonatal mortality. The current study showed that preterm birth is an independent determinant of perinatal death. The findings of this study are in agreement with those of studies conducted in Ethiopia (Addis Ababa/Finfinne, Goojjam), Zimbabwe and Brazil $(15,17,19$, and 21).

We showed that low maternal hemoglobin (anemia) is an independent determinant of perinatal mortality among our study participants. This could be due to association of low maternal hemoglobin and malnutrition, chronic diseases, and other maternal conditions. This finding is similar to the study conducted in Ethiopia, Addis Ababa/ Finfinne. ${ }^{17}$

Partograph utilization by health workers during delivery is recommended to monitor maternal and newborn's condition and to take necessary action. This study also 
Table 7 The Association Between Different Factors and Perinatal Mortality Among Public Hospital Deliveries in Iluu Abbaa Boor Zone, South West Ethiopia, 2019

\begin{tabular}{|c|c|c|c|c|c|}
\hline Variables & Category & Case & Control & Crude OR & Adjusted OR \\
\hline Maternal age & $\begin{array}{l}>19 \\
20-24 \\
25-29 \\
30-34 \\
35-39 \\
<40\end{array}$ & $\begin{array}{l}13(14.4) \\
27(30 \%) \\
6(6.7 \%) \\
6(6.7 \%) \\
24(26.7 \%) \\
14(15.5 \%)\end{array}$ & $\begin{array}{l}20(5.5 \%) \\
113(31.4 \%) \\
61(16.9 \%) \\
82(22.8 \%) \\
76(21.1 \%) \\
8(2.2 \%)\end{array}$ & $\begin{array}{l}\text { I } \\
2.720(1.2-6.14)^{*} \\
6.608(2.2-19.7)^{*} \\
8.883(3-26.3)^{*} \\
2.058(0.9-4.7)^{*} \\
0.371(0.1-1)^{*}\end{array}$ & I \\
\hline Educational status & $\begin{array}{l}\text { Cannot read and write } \\
\text { Read and write } \\
\text { Primary } \\
\text { Secondary } \\
\text { Collage and above }\end{array}$ & $\begin{array}{l}23(25.5 \%) \\
31(34.4 \%) \\
6(6.6 \%) \\
13(14.4 \%) \\
17(18.8 \%)\end{array}$ & $\begin{array}{l}25(6.9 \%) \\
123(34.2 \%) \\
83(23 \%) \\
87(24.2 \%) \\
42(11.7 \%)\end{array}$ & $\begin{array}{l}\text { I } \\
3.650(-1.8-7)^{*} \\
12.727(4.6-34.7)^{*} \\
6.157(2.7-13.9)^{*} \\
2.273(I-5)^{*}\end{array}$ & I \\
\hline Birth interval & $\begin{array}{l}>2 \text { Years } \\
<2 \text { Years }\end{array}$ & $\begin{array}{l}17(69.6 \%) \\
39(30.4 \%)\end{array}$ & $\begin{array}{l}I I \mid(47.8 \%) \\
|2|(52.2 \%)\end{array}$ & $\begin{array}{l}\text { I } \\
2.1(1.13-4)^{*}\end{array}$ & $\begin{array}{l}\text { I } \\
2.76(1.84-12.44)^{*}\end{array}$ \\
\hline ANC follow-up & $\begin{array}{l}\text { Yes } \\
\text { No }\end{array}$ & $\begin{array}{l}61(67.8 \%) \\
29(32.2 \%)\end{array}$ & $\begin{array}{l}312(86.7 \%) \\
48(13.3 \%)\end{array}$ & $3.1(1.8-5.28)^{*}$ & $2.84(1.44-4.83) *$ \\
\hline TT vaccination & $\begin{array}{l}\text { Yes } \\
\text { No }\end{array}$ & $\begin{array}{l}6 \mathrm{I}(67.8 \%) \\
29(32.2 \%)\end{array}$ & $\begin{array}{l}312(86.7 \%) \\
48(13.3 \%)\end{array}$ & I.I $(1.8-5.284)^{*}$ & \\
\hline Gestational age & $\begin{array}{l}\text { Term } \\
\text { Preterm } \\
\text { Post-term }\end{array}$ & $\begin{array}{l}26(28.9 \%) \\
58(64.4 \%) \\
6(6.7 \%)\end{array}$ & $\begin{array}{l}348(96.6 \%) \\
6(1.7 \%) \\
6(1.7 \%)\end{array}$ & $\begin{array}{l}\text { I } \\
\text { I3.4(4-44.4)* } \\
0.103(0.025-0.424)\end{array}$ & $\begin{array}{l}\text { I } \\
\text { I4.3(4.7-37.7)** } \\
0.16(0.057-0.235) *\end{array}$ \\
\hline Obstetric Complication & $\begin{array}{l}\text { No } \\
\text { Yes }\end{array}$ & $\begin{array}{l}12(13.40 \%) \\
78(86.6 \%)\end{array}$ & $\begin{array}{l}245(68 \%) \\
115(32 \%)\end{array}$ & $\begin{array}{l}\text { I } \\
\text { I3.8 (7.26-26.4)* }\end{array}$ & $\begin{array}{l}\text { I } \\
2.47(1.92-22.7)\end{array}$ \\
\hline Previous history of Stillbirth & $\begin{array}{l}\text { No } \\
\text { Yes }\end{array}$ & $\begin{array}{l}79(87.8 \%) \\
\mathrm{II}(12.2 \%)\end{array}$ & $\begin{array}{l}15(4.1 \%) \\
345(95.9 \%)\end{array}$ & $\begin{array}{l}\text { I } \\
3.2(1.4-7.2)^{*}\end{array}$ & \\
\hline Level of hemoglobin & $\begin{array}{l}>11 \mathrm{gm} / \mathrm{dl} \\
<11 \mathrm{gm} / \mathrm{dl}\end{array}$ & $\begin{array}{l}36(63.50 \%) \\
19(36.5 \%)\end{array}$ & $\begin{array}{l}267(86 \%) \\
42(14 \%)\end{array}$ & $\begin{array}{l}\text { I } \\
3.7(1.98-7)^{*}\end{array}$ & $\begin{array}{l}\text { I } \\
2.8(I .4-5.7 I)^{* *}\end{array}$ \\
\hline Sex of newborn & $\begin{array}{l}\text { Female } \\
\text { Male }\end{array}$ & $\begin{array}{l}30(33.3 \%) \\
60(66.6 \%)\end{array}$ & $\begin{array}{l}202(56.1 \%) \\
158(43.9 \%)\end{array}$ & $2.6(1.57-4)^{*}$ & \\
\hline Weight of newborn & $\begin{array}{l}>2500 \mathrm{gm} \\
<2500 \mathrm{gm}\end{array}$ & $\begin{array}{l}18(20 \%) \\
72(80 \%)\end{array}$ & $\begin{array}{l}335(93 \%) \\
25(7 \%)\end{array}$ & $\begin{array}{l}\text { I } \\
43(27-83)^{* *}\end{array}$ & \\
\hline Congenital anomaly & $\begin{array}{l}\text { No } \\
\text { Yes }\end{array}$ & $\begin{array}{l}74(82.2 \%) \\
16(17.8 \%)\end{array}$ & $\begin{array}{l}356(98.9 \%) \\
4(1.1 \%)\end{array}$ & $\begin{array}{l}\text { I } \\
19.2(6.2-59)^{*}\end{array}$ & \\
\hline Partograph Use & $\begin{array}{l}\text { Yes } \\
\text { No } \\
\text { Not Indicated }\end{array}$ & $\begin{array}{l}46(51.1 \%) \\
35(38.9 \%) \\
9(10 \%)\end{array}$ & $\begin{array}{l}272(75.6 \%) \\
76(21.1 \%) \\
12(3.3 \%)\end{array}$ & $\begin{array}{l}1 \\
4.4(1.8-11)^{*} \\
1.6(0.7-4)\end{array}$ & $\begin{array}{l}\text { I } \\
2(1.274-15.4)^{*}\end{array}$ \\
\hline
\end{tabular}

Notes: *P-value $<0.05$. **P-value $<0.01$.

identified lack of partograph utilization as one of the determinants of perinatal death..$^{17,20}$

Although obstetric complications, birth weight, sex of the fetus/newborn, and previous history of stillbirth have been identified previously as determinants of perinatal mortality, our study did not find significant associations with these variables.
This study was limited by its retrospective design and the fact that it relied on maternal recall data. Not all study participants had complete data. The strengths of this study were that it addressed both maternal and perinatal perspectives, as data were collected using wellstructured questionnaire and checklist (for record review). 


\section{Conclusion}

From this study we can conclude that birth interval, having ANC follow-up, premature and postterm births, maternal hemoglobin level and partograph utilization are independent determinants of perinatal mortality. These findings imply that that there is suboptimal health care service utilization by the community, as well as opportunities to improve health care service provision. Perinatal mortality may be improved by targeted education strategies and improved access to healthcare for women of reproductive age and improving provider skills and quality of health care services.

\section{Recommendations \\ For Zonal Health Officers}

Concentrated efforts to bring about behavioral change among the community to increase the level of utilization of health care service like family planning (to increase birth interval) and ANC follow-up.

\section{For Health Professionals (Health Care Providers)}

Health care providers should encourage and advise pregnant women to adhere to recommended iron and folic acid supplementation and monitor their hemoglobin level during the ANC follow-up. Health care workers should also use partograph while attending delivery as it is a useful tool to monitor progress and is associated with improved outcomes of labor.

\section{For Health Programmers (Decision Makers)}

Attempts should be made to advance the quality of health care service by advancing health care facilities and equipment necessary for care of newborns with health conditions.

\section{For Future Researchers}

Additional epidemiological studies may be helpful to identify areas for further investigation and health care facility differences; however, cohort and randomized controlled trials are more likely to identify causality.

\section{Data Sharing Statement}

All data generated or analyzed during this study are included in this published article.

\section{Ethics Approval and Consent to Participate}

The ethical approval for this study was obtained from the Research Ethical Committee of Mettu University, then informed consent was obtained from the participants, after the necessary explanation about the purpose and benefits of the study and their right on decision to participate in the study. All the interviews with respondents were done under strict privacy.

\section{Acknowledgments}

We acknowledge Mettu University for financial support. We are also grateful to the data collectors and respondents who took part in this study.

\section{Author Contributions}

All authors made a significant contribution to the work reported, whether that is in the conception, study design, execution, acquisition of data, analysis and interpretation, or in all these areas; took part in drafting, revising or critically reviewing the article; gave final approval of the version to be published; have agreed on the journal to which the article has been submitted; and agree to be accountable for all aspects of the work.

\section{Disclosure}

The authors declare that they have no conflicts of interest for this work.

\section{References}

1. USAID. Measure evaluation population and reproductive health, perinatal mortality rate. Available from: www.cpc.unc.edu/measure/evalua tion/populationandreproductivehealth. Accessed May 18, 2019.

2. UN Inter-agency Group for Child Mortality Estimation. Levels \& Trends in Child Mortality: Report 2018. Available from: https:// www.unicef.org/media/47626/file/UN-IGME-Child-Mortality-Report2018.pdf.

3. UNICEF, WHO, BANK TW, Division UNDP. Levels \& Trends in Child Mortality. Report on Estimates Developed by the UN Interagency Group for Child Mortality Estimation. 2011.

4. World Health Organization. Making Every Baby Count: Audit and Review of Stillbirths and Neonatal Deaths. WHO: Geneva; 2016.

5. Central Statistical Agency (CSA) [Ethiopia] and ICF. Ethiopia Demographic and Health Survey 2016: Key Indicators Report. Addis Ababa, Ethiopia, and Rockville, Maryland, USA: CSA and ICF; 2016.

6. World Health Organization, UNICEF. Trends in Maternal Mortality: 1990-2015: Estimates from WHO, UNICEF, UNFPA, World Bank Group and the United Nations Population Division: World Health Organization, UNICEF; 2015.

7. WHO. Managing Programs to Improve Child Health. Geneva, Switzerland: WHO; 2009. 
8. Save the Children. Save the Children's Child Protection Strategy 2013-2015. Available from: https://www.savethechildren.net/sites/ default/files/cp_strategy_final_web_email1.pdf.

9. JHPIEGO M and NHP. Monitoring Birth Preparedness and complication readiness tools and indicators for maternal and newborn health. Matern Neonatal Heal Progr JHPIEGO. 2004;1:457.

10. World Health Organization. Making Every Baby Count Audit and review of stillbirths and neonatal deaths: World Health Organization; 2016.

11. Housseine N, Snieder A, Binsillim M, Meguid T, Browne JL, Rijken MJ. The application of WHO ICD-PM: Feasibility for the classification of timing and causes of perinatal deaths in a busy birth centre in a low-income country. PLoS One. 2021;16(1):1-15.

12. UNICEF, WHO, Worldbank, UNFPA. Levels and Trends in Child Mortality Report 2013. New York: UNICEF, WHO, Worldbank, and UNFPA; 2014.

13. UNICEF, WHO, BANK TW, Division UNDP. Levels \& Trends in Child Mortality. In: Report on Estimates Developed by the UN InterAgency Group for Child Mortality Estimation; 2017.

14. Etana S, Tadesse WL, Ferede A. Assessment of Neonatal Mortality in Women Who Gave Birth Recently: a Community Based Cross Sectional Study in Lume District of Oromia Region, Eastern Ethiopia. Neonat Pediatr Med. 2018;4:146. doi:10.4172/25724983.1000146
15. Yirgu R, Molla M, Sibley L, Gebremariam A. GebremariamA(2016) Perinatal Mortality Magnitude, Determinants and Causesin West Gojam: population-Based Nested Case-Control Study. PLoS One. 2016;11(7):e0159390. doi:10.1371/journal.pone.0159390

16. Yirgu R, Metike Mola L. perinatal mortality, magnitude determinants and causes in west Gojam. PLoS One. 2001;6(11):7.

17. Getiye Y, Fantahun M. Factors associated with perinatal mortality among public health deliveries in Addis Ababa, Ethiopia, an unmatched case. BMC. 2017;1-7.

18. Hibstu DT, Ayele TA, Mangesha Z. Determinats of Neonatal mortality in Ethiopia; a ase control study. OALib j. 2014;12:254.

19. Emmanuel T, et al. Determinants of perinatal mortality in Marondera District, Mashonaland, East province of Zimbabwe: a case control study. Pan African Med J. 2011;8. doi:10.4314/pamj.v8i1.71054

20. Lona Reyes JC, Pérez Ramírez RO, Llamas Ramos L, et al. Neonatal mortality and associated factors in newborn infants admitted to a Neonatal Care Unit. Arch Argent Pediatr. 2018;116(1):42-48. doi:10.5546/aap.2018.eng.42

21. Migoto MT, Oliveira RP, Silva AMR, Freire MHS. Early neonatal mortality and risk factors: a case-control study in Paraná State. Rev Bras Enferm. 2018;71(5):2527-2534. doi:10.1590/0034-7167-20160586

\section{Publish your work in this journal}

Research and Reports in Neonatology is an international, peerreviewed, open access journal publishing original research, reports, editorials, reviews and commentaries on neonatal health. The manuscript management system is completely online and includes a very quick and fair peer-review system. Visit http://www.dovepress. com/testimonials.php to read real quotes from published authors. 